\title{
A New Approach for Delivering eLearning Courses in Jordanian Universities
}

\author{
Adnan Atoum \\ Yarmouk University, Irbid, Jordan \\ Abdallah Al-Zoubi \\ Princess Sumaya University for Technology, Amman, Jordan \\ Majed Abu Jaber \\ University of Jordan, Amman, Jordan \\ Mamoun Al-Dmour \\ University of Jordan, Amman, Jordan \\ Bashar Hammad \\ Hashemite University, Zarqa, Jordan
}

\begin{abstract}
A new approach for delivering eLearning course in Jordanian universities is presented. The main objective of this experiment is to improve the quality and relevance of eLearning at Jordanian higher education institutions through the development, implementation and teaching of an English Language course at a national level. The pilot course was designed and delivered in four Jordanian universities under strict Quality Assurance (QA) measures over several consecutive semesters. The outcomes of the pilot ensured proper assimilation of eLearning QA standards and learning outcomes.
\end{abstract}

\section{INTRODUCTION}

Jordan has always considered higher education as a strategic tool in steering and transforming the kingdom's economy and as an instrument for enhancing quality of life and social well-being of citizens [1]. The contribution of higher education to economic development has been well elaborated in all key national policy documents and a new strategy has recently been revised with the view of transforming the education sector into both an effective and efficient tool for accelerated national development.

Students' enrolment in higher education has however been growing rapidly with an average rate above $30 \%$, being one of the highest in the world, with a total number currently enrolled, both female and male, reaching a record high of over 300,000 students, over $4.6 \%$ of the population. The trend is likely to increase in the coming years and the demand for access to higher education is expected to soar. The highly strained universities, both public and private, are suffering from this massification which is placing tremendous pressure on them to open up their doors wider to the increasing numbers of students. This has placed great constraints on resources of universities specifically the inability of the system to improve student-professor ratio which stands at over 30, a quality indicator well below world standard. The present trend seems to worsen due to the brain-drain phenomena Jordan is facing and the need to recruit 
more academic staff, estimated at 6000 for the next 4 years, a matter of urgency that cannot be overemphasized.

Elearning naturally offers an appropriate solution to Jordanian traditional higher education institutions to overcome many of such challenges and obstacles [2]. Accordingly, the Ministry of Higher Education (MoHE) has articulated a national eLearning strategy for higher education in Jordan for the period 2007-2010 which clearly states the need "to support institutions of higher education in their move towards embedding eLearning appropriately using technology to transform education into a learner centric system that is internationally distinguished in its quality and impact, to foster innovation and excellence in teaching and learning, and to support employability of lifelong learning" [3]. In fact, the higher education policy stresses on the need to promote use of ICT (Information and Communications Technology) for teaching, learning and networking of universities in order to ease the pressure on its limited available resources. Providing universities with high quality connectivity and eLearning services in order to enhance the efficiency and quality of teaching and learning are top priority issues. As such, universities have sought alternate forms of delivery to fulfill demand and need to transform into new-generation institutions where blended and e-learning and interactive approach among group of learners has become a challenging pedagogy of the learning process in Jordan.

However, efforts to integrate and embrace Technology-enhanced Learning (TeL) in university education over the past decade have been limited in scope and modest in achievements and success, mainly due to cultural and quality assurance issues and considerable technological infrastructure hindrances [4-10].

In this paper, efforts to address and overcome obstacles that have hindered the development TeL in universities, mainly quality assurance concerns and qualms, are discussed. In particular, an outline of strategic issues is described, focusing on a new initiative aimed at assisting both MoHE and the Higher Education Accreditation and Quality Assurance Commission (HEAC) to boost efforts and support institutional policy revision and development related to the quality and delivery of online courses. Consequently, the outcomes of a project funded by the European Commission under the TEMPUS programme are presented, mainly piloting one online course delivered to students in a number of universities simultaneously.

\section{Enhancing Quality of Technology-Enhanced Learning at Jordanian Universities}

New developments in pedagogy and technology provide learners, teachers, organisations and society at large, with enormous advantages, including better access to higher quality of learning and teaching, increased effectiveness of and extension to the capacity of the institution, economic advantages and better quality of assessment and benchmarking [10-18]. Such benefits have long been recognized by MoHE and HEAC, the two governmental authorities trusted with reform of higher education in the country. Both have given strong support for initiatives of developing new legal acts for regulating accreditation of TeL at national system levels. In fact, MoHE and HEAC have placed the matter of developing standards for the assessment of quality in TeL as a top priority. The law of higher education strongly supports development of e-Education and accordingly, universities have already taken steps towards its implementation. However, the legislations in the law for defining accreditation process in higher education institutions has only recently included specific clauses for TeL and its quality significantly varies and is oriented towards implementing courses rather than full programmes. In 2010, HEAC has defined the initial rules and regulations on accreditation standards for TeL study programmes but these remain the basic tools for assuring quality measured as state wide threshold standard. Still, self-assessment and quality review of TeL 
programmes remains a major obstacle. As a matter of urgency, these authorities need to define in detail amendments in existing legislations for quality assurance in higher education, where various forms of TeL including distance and web-based learning.

To overcome and improve the situation, a consortium of five Jordanian universities, together with MoHE and HEAC, as well as three European universities and two QA agencies have come up with an initiative through the implementation of a project funded by the European Commission under the TEMPUS programme. The project entitled: "Enhancing Quality of Technology-Enhanced Learning at Jordanian Universities", EQTeL, was granted by the European Commission to the consortium in December 2013 for a 3-year duration, http://eqtel.psut.edu.jo/Home.aspx. The wider objective of EQTeL is to promote reform and modernization of higher education in Jordan through the introduction of a national quality assurance system for technology-enhanced learning, and improve, develop and implement accreditation standards, guidelines and procedures for quality assurance of TeL courses and study programmes at a national level. Consequently, new standards to assimilate the quality of TeL courses may be introduced and incorporated into existing legal acts and regulatory documents at both institutional and national levels. Simultaneously, implementation of the new standards will be ensured through establishing a capacity building programme that provides extensive training for all levels of staff involved in accreditation or delivery of TeL programmes, from teaching staff, trainers, evaluators, official accreditation reviewers and higher education public authorities. In addition, the project is seeking the possibility to develop a close connection with the Bologna 3-degree cycle structure to allow for better definition and positioning of the training programmes.

In order to investigate the perception of students and staff, and to test quality assurance standards and procedures, three pilot courses have been selected, designed and delivered through joint efforts of the Jordanian universities with strong support from MoHE and HEAC and significant help from EU partners. Continuous piloting and monitoring of the quality of the courses was maintained over a period of three semesters in order to examine the assimilation and comprehension of students as well as perception and acceptance of the professoriate. Such approach may introduce a gradual change of culture and impact the quality on a system level which would bring significant benefits to all prospective students in Jordan and the wider Middle East region.

\section{Development of Pilot eLearning Course}

One of the pilot courses selected in this project was the English Language which is offered at the first year of studies to all university students in Jordan. The course was designed in eLearning format by a team of specialists led by Yarmouk University. The design revolved around building a student centered classroom and consisted of three known phases of planning and design, development and implementation, and course delivery and management. The planning and design phase centered around discussing major pedagogical questions in terms of how the online instructional design are different from the face-to-face classroom and to what extent the current eLearning system at universities can support the implementation of the different teaching methods and instructions. Based on these discussions, the team developed a shared-vision of delivery strategies and course instruction including lecture notes, group discussion, formative assessment, summative assessment, and video demonstration, and course activities. The development and implementation phase consisted of the following steps:

1. Identifying textbooks and starting gathering content materials for the course.

2. Identifying learning outcomes. 
3. Mapping out the relationship between content units and assessment, and selecting which assessment methods were appropriate for the learning outcomes. Multiple assessments methods were chosen to provide students with ample opportunities to demonstrate learning; for example, pre-quizzes that assess the students before they read the chapter and start the activities in the unit used.

4. Identifying supplemental materials such as YouTube, educational videos, online lectures materials that can support students if they needed additional help during the course.

5. After preparing the teaching materials, transferring all content materials into the eLearning system and setting up course components into course site.

In fact, the course was composed of seven units. Each unit was divided into three basic sections: grammar, reading and vocabulary. The grammar section started with brain storming exercises followed by explanation of the grammar points in the unit. The second section was reading in which students read a text on a topic familiar to them dealing with issues related to their daily life, cultural issues, or major trending topics on the media. Students were encouraged to read the text to make sure that they comprehend the intended material. Vocabulary items were also presented in this section were words that students came across in the previous two sections. The vocabulary section not only taught students' words and their meanings but also strategies to help understand the meaning of words and how to use them in various contexts.

Each section contained objectives and learning outcomes, the pre-required materials that students had to do before they started the section, the assigned readings and activities for the that section, and the post assessment materials, and post-self-assessment quizzes with automated feedback were introduced after each module/section in order to test the knowledge acquired by the students. Each section also contained supportive material/tutorials which provided additional explanations for students. The online assessments were designed in a way that gives students the chance to re-take the assessments as much as they need. Several types of questions were used in the self-assessment quizzes like multiple-choice questions and true/false questions. These quizzes were graded automatically and all grades were archived to allow the tutor to track students' progress throughout the course.

Formal quizzes, midterm and final exams that assess each of the learning objectives were designed and conducted online. These quizzes and exams were held using Moodle in a certain computer lab at specific times announced to the students in the "Course and Study Guile" taking into consideration all authentication measures under faculty members' supervision. Questions could have a variety of styles. The student obtained his/her grade upon the completion of each quiz or exam with a feedback about his/her answers. Online homework assignments were also assigned to students. These assignments were managed using the Moodle page of the course where the instructor posted the assignment with the due date, and students uploaded their response (as a word or pdf file) for grading. The instructor would then grade students' assignment and upload their grades and feedback comments for each student. A sample of the course design is shown at the link: www.youtube.com/watch? $\mathrm{v}=8 \mathrm{M} 7 \mathrm{gj} 3 \mathrm{bVxBw}$.

\section{Development of eLearning Virtual Platform}

A Virtual Leaning Environment (VLE) was developed as a platform that hosts and manages the delivery of the proposed e-course. The Hashemite University, working closely together with University of Jordan and Princess Sumaya University for Technology, set the on-line learning strategies to select proper VLE tools for designing and adopting the eLearning courses: English, Renewable Energy and Communication Engineering Lab into VLE. It was decided to implement 
Moodle open source platform as the Learning Management System (LMS) in the VLE with its plugins and other software tools to manage e-content, virtual class rooms, assignments, task submissions and grading, quizzes, exams, tasks queue, lab booking, and scheduling online experiments. The team agreed on how to integrate the courses into the VLE and discussions on roles and responsibility were carried out among Hashemite University, University of Jordan, and Princess Sumaya University for Technology.

The VLE was then hosted at a special PSUT server dedicated for this purpose. The VLE is accessible via the URL http://eqtel-vle.psut.edu.jo/moodle. The VPN IP Address is 193.188.67.34 and the Server IP Address: 172.31.0.20. The VLE specifications are the following:

- Moodle version 2.8. +

- PHP version 5.4.7

- MySQl version 5.5.27

In addition, four types of accounts were created; administrator, teacher, student and guest. Proper privileges were given to these accounts according to their roles. Suitable educational and teaching material were selected for all courses with large effort spent on integrating the remote lab to this VLE, such that both courses and Communication Engineering Lab are delivered by full interactivity and offering flexibility of content delivery and the opportunity for shared social learning between partner institutions. All materials for the eLearning courses needed to complete the content in a traditional way were prepared and designed by Yarmouk University, Hashemite University, and Princess Sumaya University for Technology.

Hashemite University, University of Jordan and Princess Sumaya University for Technology led efforts in the personalization process of VLE and tools were properly selected in order to suite the courses, students and professors. Selection of the learning tools included synchronous and asynchronous modes, project-based learning, cooperation tools, assessment and evaluation, as well as social media tools as complement of the learning process. The environment of the VLE and its content including the eLearning courses may be accessed by students when enrolled at their own university. Students can access the course topic by topic or chapter by chapter. A description of each topic was given prior to accessing the actual content of each chapter to enable students to familiarize themselves with the scientific subjects.

The first field that students face is the "Welcoming Section". It contains the following:

- Brief description of the course and its objectives

- Teacher's Responsibility while teaching online class:

- Student's responsibility while navigating the online course

- Syllabus of the course

- Course and Study Guide, which constitutes the backbone of the course. It changes depends on the semester and university at which the course is being offered. It included:

- Days, dates and week number for the semester the student enrolls in

- University event (classes begin, exams, etc.)

- Material that students should study during that week

- Dates of weekly quizzes, midterm exam

- Assignments (posting and due dates)

- Date and time for traditional and virtual office hours 
Several synchronous and asynchronous communication mechanisms were employed in the courses with an emphasize on the synchronous ones. Synchronously, virtual classrooms were conducted periodically in order to help the students, answer their questions and guide them through the learning process. A complete description of VLE description and access and the integration of the courses and the labs is given by the video at the home page of the project's website http://eqtel.psut.edu.jo/Home.aspx.

\section{STATEMENT OF THE PROBLEM}

In order to test QA standards and intended learning outcomes (ILO) in the pilot English Language course, a team from MoHE and HEAC have joined academicians from partners' universities to explore the possibilities of ensuring high quality of its content and delivery. The effectiveness of teaching the e-course at three Jordanian universities in comparison to the traditional method in teaching the same course with same content was subsequently investigated. To achieve this objective, the following questions were addressed:

1. Were the eLearning courses effective from the perspective of the students?

2. How effective were the instructors teaching the eLearning courses from the perspective of the students in comparison to traditional learning courses?

3. Were there any statistical differences in students' grades in the eLearning method in comparison with the traditional learning method?

4. What are students' attitudes toward the English Course?

5. What feedback can be drawn from faculty members, technicians, and students supporting the delivery of the courses?

\section{Approach of Study}

The sample of the initial study consisted of 264 undergraduate students enrolled in five online classes at Yarmouk University in the spring semester 2015-2016, with another 542 undergraduate students enrolled in 10 sections at Yarmouk University, Princess Sumaya University for Technology (PSUT), Hashemite University in the summer semester of 20152016. The classes at each university were divided into two groups; half the sections represented the experimental group which was taught through eLearning method while the other classes represented the control group and were taught through the traditional method. The distribution of the sample is shown in Table (1).

\begin{tabular}{|c|c|c|c|c|}
\hline \multirow{4}{*}{$\begin{array}{c}\text { Semester } \\
\text { Spring 2015- } \\
2016\end{array}$} & \multicolumn{3}{|c|}{ Table (1): Distribution of Sample. } & \multirow[b]{2}{*}{ Total } \\
\hline & University & Groups & No. & \\
\hline & Yarmouk & Experimental & 122 & \multirow{8}{*}{542} \\
\hline & & Control & 142 & \\
\hline \multirow{6}{*}{$\begin{array}{c}\text { Summer } \\
2015-2016\end{array}$} & Yarmouk & Experimental & 190 & \\
\hline & & Control & 199 & \\
\hline & Princess & Experimental & 22 & \\
\hline & Sumaya & Control & 22 & \\
\hline & Hashemite & Experimental & 24 & \\
\hline & & Control & 85 & \\
\hline
\end{tabular}

In addition to the English eLearning course development and design, five methods were used to assess the effectiveness of the eLearning method in comparison to the traditional method:

1. Students' attitudes questionnaire which aimed to explore students' attitudes toward learning English at the end of the semester. The questionnaire consisted of 10 items with 5 Point-Likert-Type responses that ranged from strongly agree to strongly 
disagree. Validity and reliability indicators for the questionnaire were established. First, correlations between item scores and the total score ranged from 0.41 to 0.64 indicating good construct validity. In addition, a Cronbach alpha value of 0.90 for all 10 items indicating an excellent reliability indicator which implied that the questionnaire was reliable to be used.

2. ELearning course evaluation questionnaire aimed to explore students' evaluation of eLearning method at the end of the semester. The questionnaire consisted of 16 items with 5 Point-Likert-Type responses that ranged from strongly agree to strongly disagree. The scale consisted of four subscales that measure course content evaluation, instructor evaluation, technology use evaluation, and technical support evaluation. Validity and reliability indicators for the questionnaire were established. First, correlations between item scores and the total score ranged from 0.37 to 0.87 indicating good construct validity, and correlations between subscales scores and total scale scores ranged between 0.85 to 0.92 . A Cronbach alpha value of 0.95 for all 16 items was obtained indicating an excellent reliability indicator which implied that the questionnaire was reliable to be used.

3. Yarmouk University instructor's evaluation scale, a mandatory standardized scale used to evaluate all instructors. The scale consisted of 20 items with 5-point- Likert-Type responses that range from strongly agree to strongly disagree.

4. Student's final grades which consisted of the midterm and final exams in addition to the quizzes taken during the course. All grades for all sections were drawn electronically from the university system through the general registration office.

5. Faculty and staff feedback collected from students through an open question requesting positive and negative aspects of the course and suggestions for improvement. Additionally, all faulty members that taught the course were asked to give feedback regarding satisfaction with the workload in the eLearning course and with the management and design of the eLearning course, as well as recommendations for changes.

The study was then implemented in the followings steps:

1. The eLearning course was developed by a team led by Yarmouk University experts in the period May 2015-October 2015.

2. The course content and design was presented to European partners through all stages of development and feedback, ideas and recommendations were exchanged during the processes.

3. The course was presented to all Jordanian and European partners in October 2015 for final approval.

4. Classes were offered during the spring and summer semester 2015-2016 and divided randomly into experimental sections (eLearning method) and control sections (traditional learning).

5. An orientation workshop was conducted to all instructors a week before the beginning of the semester to familiarize them with course.

6. Students in the experimental sections were called for two orientation meetings with the team members in order to explain the teaching methods, course design and requirements.

7. All questionnaires were administered at the end of the semesters electronically.

8. Data concerning evaluating the instructors and grades were obtained from the office of registration at the university.

9. All data was encoded and analyzed statistically using SPSS v.22. 


\section{Piloting Course and Delivery}

The course delivery and management phase consisted of providing the following:

1. Two orientation sessions for students in which the technical team explained how to use the online Moodle platform and navigate the different tools. The instructors explained the course objectives, completion requirements, expectations of students' participation, and instructor's contact information and office hours.

2. Video tutorials as students logged in to the course to help them navigate through and understand its structure.

3. "Welcoming Section" prior to start the course which contained a brief description of the course and its objectives, teacher's responsibility while teaching online class, student's responsibility while navigating the course, syllabus, and Course and Study Guide which described in above in details.

4. Instructions of certain activities were available in English and Arabic.

\section{RESULTS AND DISCUSSION}

First: to answer the first question regarding "Were the eLearning courses effective from the perspective of the students?", arithmetic means from the ELearning Course Evaluation Questionnaire were calculated based on data collected from various universities and shown in Fig. (1) for the Spring and Summer semesters.

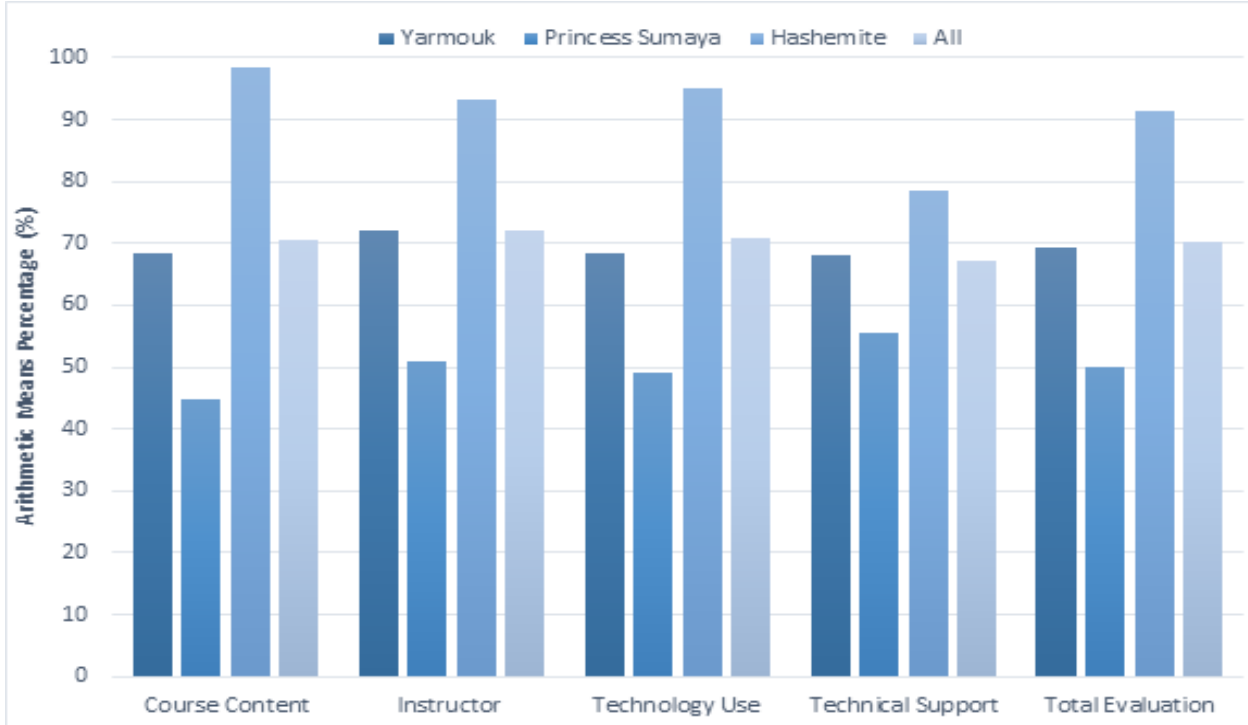

Fig. (1): Arithmetic Means of Students' Evaluation of eLearning Courses.

The results in Table (2) and Figure 1 revealed moderate levels of evaluation of the eLearning courses in general, arithmetic mean of the English course across all universities in the summer semester was $70.2 \%$ and in the spring semester was $67.6 \%$. Furthermore, sub-scale arithmetic means ranged from $65.2 \%$ to $98.5 \%$ which suggested a moderate to a high level of evaluation. However, when examining the arithmetic means across both semesters in all universities, means ranged from $44.8 \%$ to $95.2 \%$ suggested the need to review the content and design of some aspects of the course to improve those elements with low means. These findings are considered positive since this is a new experience for Jordanian universities in EL courses and further improvement of the course design and content will improve the evaluation of this course.

Second: To answer the second question regarding "How effective were the instructors teaching the eLearning courses from the perspective of the students in comparison to 
traditional learning courses?" arithmetic means of students' evaluation of their instructors are shown as in Fig. (2).

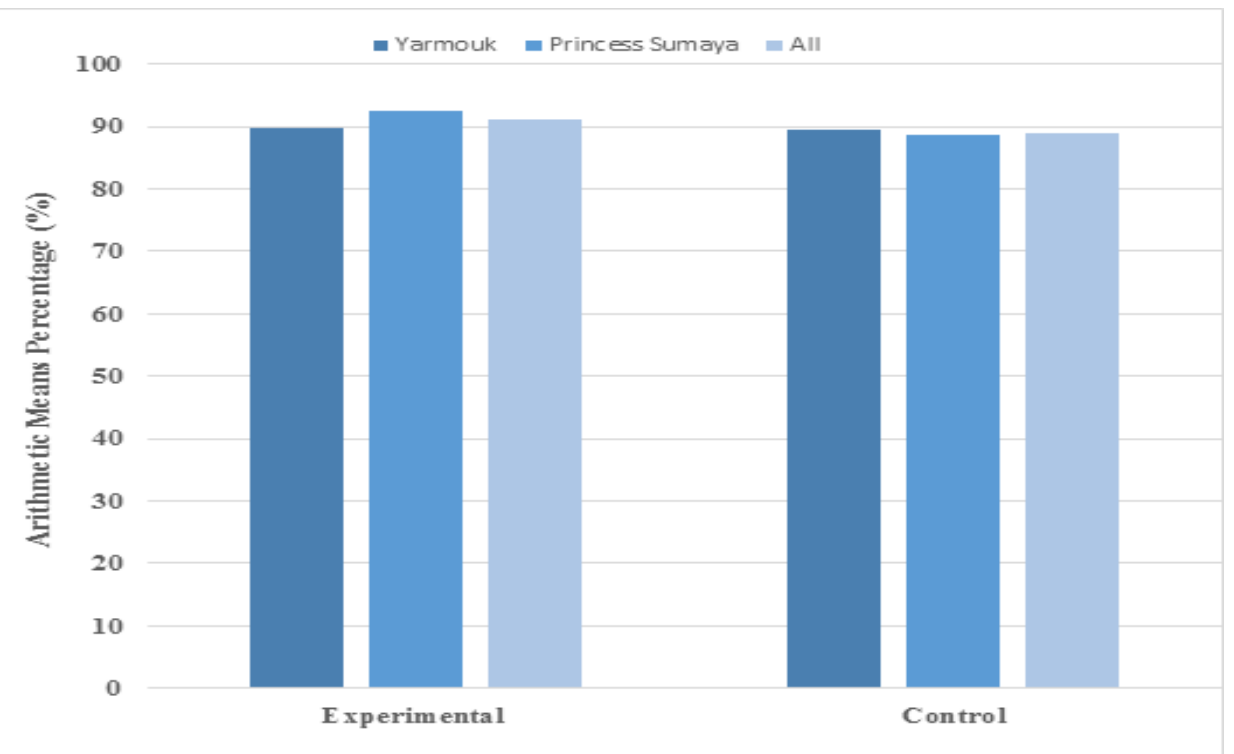

Fig. (2): Arithmetic Means of Students Evaluation of Instructors in Experimental and Control Groups.

Fig. (2) shows that students' evaluation of instructors teaching the eLearning course did not differ significantly from evaluating instructors teaching the same traditional courses $(\mathrm{t}=54$, Ns.). However, total means of faculty evaluations were higher in the experimental groups that used the eLearning method (91.1\%) compared to means of the control groups that were taught using the traditional learning method $(89.0 \%)$ indicating that faculty members using the eLearning method were more favorable than when teaching traditional learning method. It is worth mentioning here that faculty members who taught the experimental groups were the same individuals who taught the control groups.

Third: To answer the third question regarding "Were there any statistical differences in students' grades in the eLearning method in comparison with the traditional learning method?", means of students' grades for the eLearning and traditional learning methods were calculated as shown in Fig. (3). 


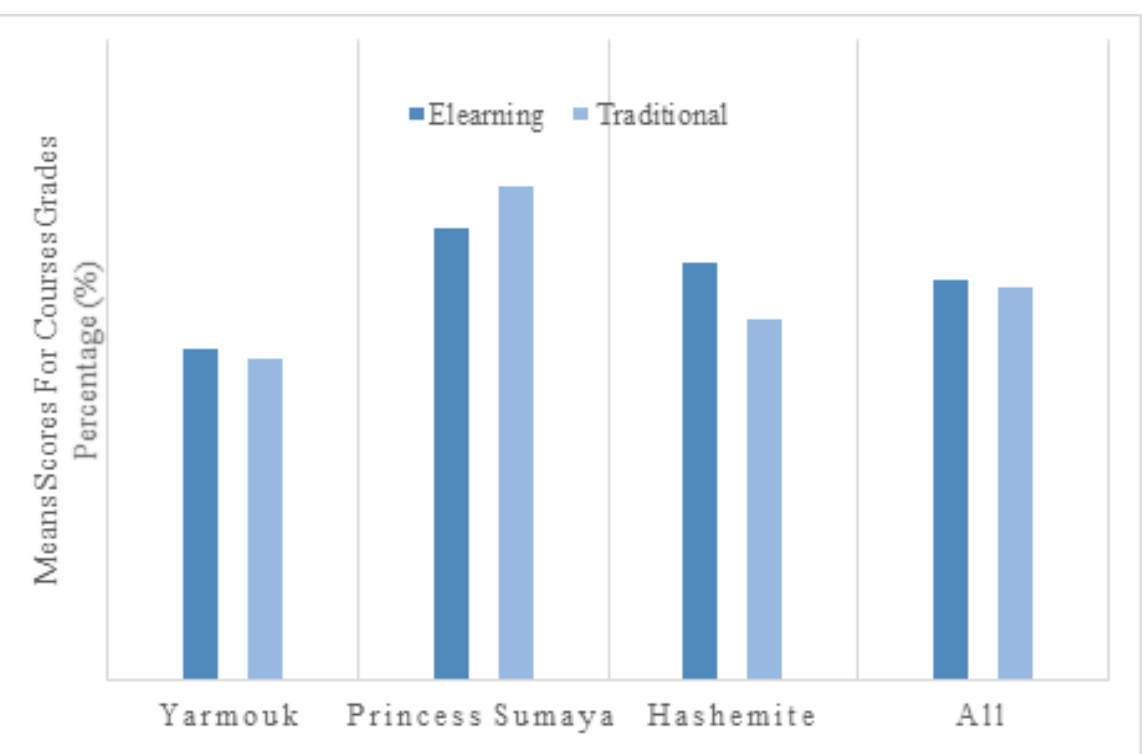

Fig. (3): Arithmetic Means Scores for Courses Grades for eLearning and Traditional Learning Methods.

Fig. (3) shows that means of students' eLearning method grades did not differ significantly from traditional learning method grades in the course for both semesters $(\mathrm{t}=.22$, $\mathrm{ns}$. \& $\mathrm{t}=.41$, Ns.). Means were very close in both methods of learning indicating that grades of students were not affected by the new method of learning.

Fourth: To answer the fourth question regarding "What are students' attitudes toward the English Course?", means of students' attitudes toward the English course for both the eLearning method and the traditional method are calculated as in Fig. (4).

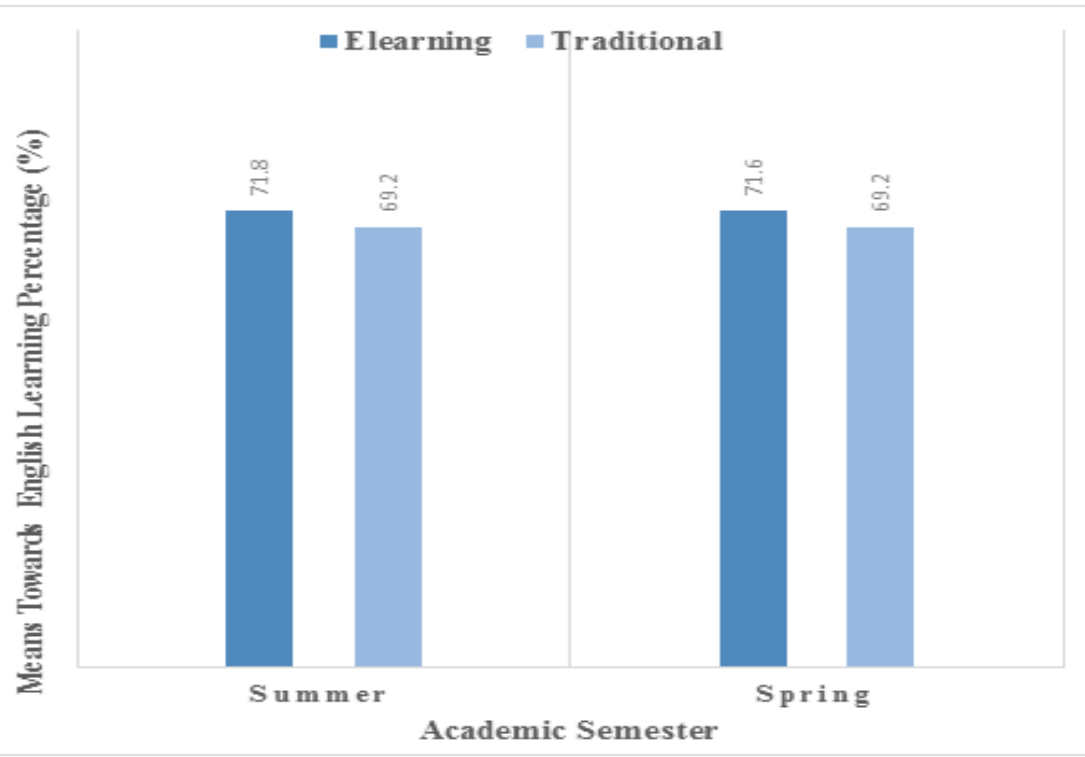

Fig. (4): Arithmetic Means of Students Attitudes Toward English Course Based On Method of Learning in Yarmouk University.

The results show that means of students' attitudes toward the English course in the experimental groups that were taught using eLearning method were not significantly different than control groups that were taught using the traditional learning method $(t=1.21$, ns. \& $\mathrm{t}=1.04$, Ns.). However, when examining the means of the students' attitudes in the experimental and control groups for both semesters, it is worth noticing that students' 
attitudes in the experimental eLearning groups were higher than the traditional method in control groups indicating a slight advancement in students' attitudes of the eLearning groups.

Fifth: To answer the fifth question concerning "What feedback can be drawn from faculty members, technicians, and students? All stakeholders involved in the eLearning English course were asked to give their positive or negative experiences and any suggestions to improve the quality of the eLearning course. Feedback was received and summarized based on a frequency of 3 ideas or suggestions. The analysis revealed the following findings.

All faculty members expressed their satisfaction with the experience especially in terms of the quality of online education in general. Some students were however not serious in following up with course activities. Faculty members faced the same challenges in teaching both face-to-face and online courses and emphasized the need of orientations to both faculty members and students at the beginning of the semester. Faculty members also expressed the need to show instruction to the English course activities in Arabic.

The majority of students liked the course and a small minority of students expressed dislike or discomfort with the course. Students from three different universities in the eLearning classes responded to an item in the ELearning Evaluation Questionnaire which stated: "I would recommend this course to my friends" with 65\% in favor. Also, their feedback included difficulties with the system such as it was slow or it went down sometimes, too many quizzes and not enough time to prepare for the quizzes.

For Technicians, there was a need for more instructions in Arabic, texts were rigid or incomprehensible and needs action or sounds and voices, there is a need for more videos to explain materials or applications and in developing a questions bank.

In general, the results support the notion that the quality and learning outcomes of the eLearning method in teaching the English course was not significantly different from those of the traditional method of learning for the same course with the same content in four different measures that included evaluations of the instructors, course grades, attitudes toward the course, and evaluations toward the course itself. In spite of the previous non-significant differences in the indicators between the experimental eLearning groups and the traditional learning control groups, mean scores for students' evaluation of their instructors, course grades, and students' attitudes toward the course were all in favor of the experimental eLearning groups. Furthermore, the non-significant differences between the experimental eLearning groups and the traditional learning control groups was a good achievement since teaching eLearning courses was a new experience in Jordanian universities and the English course was considered a difficult course for most Jordanian students as clearly indicated by both faculty members and students.

Regardless of the some of the negative observations or recommendations made by some students or faculty members, teaching an online course was a positive experience by the majority of faculty members, students and technicians based on their testimonies. The pilot eLearning course may thus help in enhancing quality of higher education and ILO overtime and may provide a base to introduce innovative teaching and learning methods that impact polices and empower the higher education system with flexibility, openness and compatibility with international standards. 


\section{CONCLUSIONS}

A new approach for delivering a eLearning course in Jordanian universities was presented in order to provide evidence for possible successful adaptation of technology enhanced-learning that may form an important pillar in higher education reform in the country. In fact, the evidence may be directed mainly towards the professoriate which seriously need a paradigm shift and mindset change in order to uptake, absorb and acclimate new realities in the scenery of both university education and technology evolution. The tremendous pressure on universities that have strained their resources to the limits leave no option but to opt for new pedagogical and teaching methodologies including eLearning. Over a decade has been lost in hesitation and confusion on the reasons behind the deadlock in reform in higher education, particularly in the light of great success and expansion of ICT adaptation and utilization in the country. The present findings will provide some incentives to those who are interested in change towards enhancing quality of learning through enhancing of technology at Jordanian Universities.

\section{References}

Adnan Badran, "New trends in Higher Education in Jordan. Education, Economic and Development", 4th ArabTurkish Congress of Social Sciences, Turkey, 26-27 October, 2014.

Fawzi Ishtaiwa, "Factors Influencing Faculty Participation in E-Learning: The Case of Jordan”, Doctoral Dissertation, University of Washington, Seattle, USA, 2006.

Jordan National eLearning Strategy for Higher Education (2007-2010), https://www.uop.edu.jo/download/research/members/Gissa-elearn-jordan.pdf.

Ahmad Al-Adwan and Jo Smedley, "Implementing eLearning in the Jordanian Higher Education System: Factors Affecting Impact”, International Journal of Education and Development Using Information and Communication Technology, Vol. 8, Issue 1, pp. 121-135, 2012.

Amer Al- Adwan, Ahmad Al-Adwan, and Jo Smedley, Exploring Students' Acceptance of e-Learning Using Technology Acceptance, Model in Jordanian Universities", International Journal of Education and Development using Information and Communication Technology, Vol. 9, Issue 2, pp 4-18, 2013.

Sinaria Abdel Jabbar, Iman Betawi and Muhannad Al-Shboul, "ICT Based Education at the University of Jordan", International Journal of Instructional Technology and Distance Learning, Vol. 10, Issue 4, pp 3-20, 2013.

Alomari, A.M., "Investigating Online Learning Environments in a Web-based Math Course in Jordan”. International Journal of Education and Development using Information and Communication Technology, Vol. 5, Issue 3, pp. 1936, 2009.Assaf, W., Elia, G., Fayyoumi, A. and Taurino, C., "Prospects of e-Learning: The Case of Jordan", Proceeding of IADIS International Conference on E-Society, Portugal, pp.152-160, 3-6 July 2007.

Dirani, K. and Won Yoon, S., "Exploring Open Distance Learning at A Jordanian University: A Case Study", The International Review of Research in Open and Distance Learning, Vol. 10, No. 2, pp.31-48, 2009.

Al-Jaghoub, S., Al-Yaseen, H., Hourani, M., Al-Haddadeh, R. and Salim, M., "E-Learning Adoption in Higher Education in Jordan: Vision, Reality and Change", Proceedings of the European and Mediterranean Conference on Information Systems, pp.146-158, Izmir, Turkey 13-14 July 2009.

Khasawneh, A., "Using Internet Technology to Support Flexible Learning in Jordan: A Case of Hashemite University', International Journal of Innovation and Learning, Vol. 8, No. 1, pp.1-10, 2010.

Adhaileh, M., 'Elearning in Jordan, Challenges Facing E-Learning in The New Millennium', in Demiray, U. et al. (Eds.): Cases on Challenges Facing e-Learning and National Development: Institutional Studies and Practices, pp.317-334, Anadolu University, Turkey, 2010.

Diabat, B., "The Extent of Acquiring E-Learning Competencies by Faculty Members in Jordan Universities", European Journal of Social Sciences, 27 (1), pp 71-81, 2011.

Fawzi Ishtaiwa, "Faculty Attitudes and Use of Moodle Course Management System as a Supplement to Face-toFace Instruction: A Jordanian Case Study”, Journal of Educational and Psychological Sciences, 12 (1), 11-44, 2011.

Mirza, A. A. and Al-Abdulkareem, M., "Models of eLearning Adopted in the Middle East", Applied Computing and Informatics, 9 (2), 83-93, 2011. 
Qteishat, M., Alshibly, H. Ja'far Alqatawna, J., and Al-Ma'aitah, M, "Factors Influencing the Adoption of eLearning in Jordan: An Extended TAM Model”, European Journal of Business and Management, 5 (18), 2013.

Muhannad Al-Shboul, Osama Rababah, R Al-Sayyed, Ghaleb Sweis and Hanadi Aldreabi, "Roadmap to Advance eLearning Management System at The University of Jordan”, Journal of American Science, Vol. 9, Issue 1, pp 531$545,2013$.

Muhannad Al-Shboul, Faculty Members' Perceptions of E-Learning at The University of Jordan”, International Journal of Instructional Technology and Distance Learning, Vol. 11, Issue 10, pp 3-44, 2014.

Ebaa Fayyoumi, Sahar Idwan Khalid Al-Sarayreh and Randa Obeidallah, "E-learning: Challenges and Ambitions at Hashemite University", International Journal of Innovation and Learning, Vol. 17, No. 4, 2015.

\section{ACKNOWLEDGMENTS}

This work has been accomplished through activities of the TEMPUS project entitled: "Enhancing Quality of Technology-Enhanced Learning at Jordanian Universities", EQTeL, project number 544491-TEMPUS-1-2013-1-ES-TEMPUS-SMGR, approved by the European Commission under grant agreement for 2013-4568, for the years 2013-2016. The authors acknowledge with gratitude the generosity of the European Commission for its efforts to modernise and reform higher education in Jordan 